\title{
Influence of the interface reinforcement on static performance of concrete composite $\mathrm{T}$-shaped beams
}

\author{
Lukasz Jabłoński ${ }^{1}$, Anna Halicka \\ ${ }^{1}$ Faculty of Civil Engineering and Architecture; Lublin University of Technology; \\ 40 Nadbystrzycka Street, 20-618 Lublin, Poland; \\ l.jablonski@pollub.pl (DD 0000-0002-9221-8335 \\ ${ }^{2}$ Faculty of Civil Engineering and Architecture; Lublin University of Technology; \\ 40 Nadbystrzycka Street, 20-618 Lublin, Poland; \\ a.halicka@pollub.pl (D) 0000-0001-5526-8862
}

\begin{abstract}
The tests results of composite reinforced concrete T-shaped beams with an interface between the web and the flange are presented. The interface in the beams differed in the degree of the adhesion activity and the joining reinforcement ratio. Five series of beams were tested for deflection, displacement of composite parts in relation to each other, strain of main and transverse reinforcement, and crack pattern. The results were compared with the theoretical forces at which interface cracks and achieves the bearing capacity, calculated in accordance with $f i b$ Model Code 2010.
\end{abstract}

Keywords: concrete composite beam, interface reinforcement, T-shaped beams

\section{Introduction}

The aim of joining two concrete elements into a one structure is to obtain the quasi-monolithic structure with a load bearing capacity greater than a sum of load capacities of the components. The consideration of such a structure as a quasi-monolithic one is allowed only if the interface between joined elements is correctly arranged. Structural connection provides technological advantages, e.g., enables partial prefabrication or stage production and determines the effectiveness of repairs or enhancements of existing structures. Therefore, it is important to identify the interface stress-strain characteristics, including ultimate load and stress, which causes the interface crack. The influence of these parameters on the static performance of the composite element has already been repeatedly described by researchers in relation to rectangular reinforced concrete elements [1]-[4]; in the rare cases - T-shaped beams [5]-[7].

The authors of this paper have already conducted research on T-shaped composite beams, in which they analysed the influence of the interface location [8], [9] and the influence of variously arranged interface parameters on the static performance of such beams [10]-[13]. 
This paper describes the development of the previous investigations with the (S2) beams with interface adhesion broken by use of PVE membrane. Two subseries A and B of the S2 series with various interface reinforcement ratios were tested.

The results of the new subseries investigations have been incorporated into a joint analysis, which is presented below. The reported results include: damage mechanism, crack and failure loads, deflections and displacements of components at the end of the element in relation to each other, strain of the main and transverse reinforcement. In addition, the work compares the obtained results with the theoretical values computed in accordance with the guidelines contained in $f i b$ Model Code 2010.

\section{Elements investigated and tests}

The T-shaped composite beams with the variously arranged interface, located between the web and flange were tested. Their dimensions were: $1800 \mathrm{~mm}$ in span length, $640 \times 50 \mathrm{~mm}$ flange cross-section, and $80 \times 150 \mathrm{~mm}$ web cross-section (Fig. 1). The beams were designed to be damaged in the support zones. The procedure of a beam production was divided into two stages. First, the concrete mix forming the web was placed in the mould. After compacting the concrete mix, the contact surface was left in its natural state. The average value of roughness depth was about $4 \mathrm{~mm}$ (height from peak to valley) therefore the surface of the interface was classified as "rough". Next, after 14 days of concrete moisturizing and preparing an "old" concrete surface (by wire brushes to delete the cement milk) the mould was completed with a layer of a "new" concrete. The longitudinal reinforcement consisted of two Ø14 mm bars (the longitudinal reinforcement ratio was $2.21 \%$ ), while the upper reinforcement consisted of two $\varnothing 8 \mathrm{~mm}$ bars. Stirrups made of $\varnothing 4 \mathrm{~mm}$ wires were used.

Five series of beams were performed with the interface arranged as follows:

- $\mathrm{BZ} / \mathrm{P}+\mathrm{S}-$ reinforced interface $\left(\rho_{\mathrm{i}}=0.21 \%\right)$ with adhesion,

- $\mathrm{BZ} / \mathrm{P}$ - non-reinforced interface with adhesion,

- BZ/S1 - reinforced interface $\left(\rho_{\mathrm{i}}=0.21 \%\right)$ with the surface of the ,old” concrete treated using a chemical agent in order to limit the adhesion,

- $\mathrm{BZ} / \mathrm{S} 2$ - reinforced interface (BZ/S2/A subseries $-\rho_{\mathrm{i}}=0.21 \%, \mathrm{BZ} / \mathrm{S} 2 / \mathrm{B}$ subseries $\rho_{\mathrm{i}}=0.42 \%$ ) with adhesion broken by use of the PVE membrane.

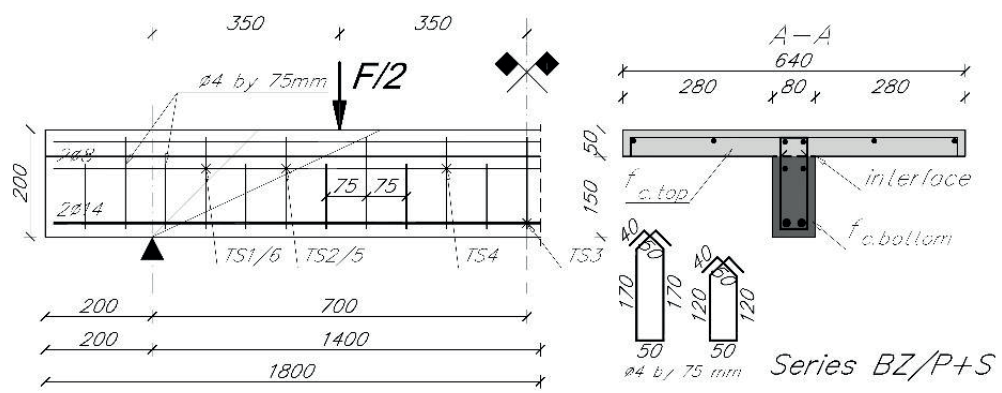

Fig. 1. Details of beams tested: a) longitudinal section, b) cross-sections; TS1/6, TS2/5, TS4-strain gauges on the stirrups, TS3 - strain gauges on the main bar. Source: own study 
The beams were tested as simply supported ones in the four-point bending test. In order to ensure stability, the beams were inverted upside down and the load was applied using a rigid traverse (Fig. 2).

In each series, three beams were tested. The load of one beam in each series was constantly increased with $0.5 \mathrm{kN} / \mathrm{min}$ rate. For the other beams in the series, the load was stopped at intervals of $10 \mathrm{kN}$ to register the width and pattern of cracks. Deflection and strain of bars were measured automatically by LVTD and strain gauges.

The steel and the concrete parameters of the "bottom" and the "top" layer were conducted using standard laboratory testing methods on reference specimens for each series. Average values of material parameters are listed in Table 1.

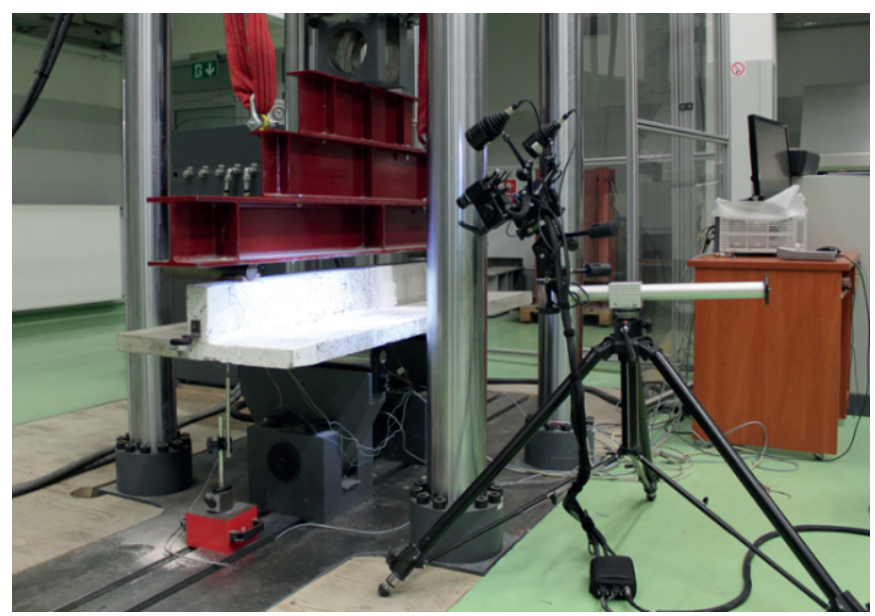

Fig. 2. A view of the beam prepared for the test. Source: own study

Table 1. Average values of material parameters. Source: own study

\begin{tabular}{llll}
\hline & $\begin{array}{l}\text { Compressive Strength } f_{\mathrm{cm}} \\
{[\mathrm{MPa}]}\end{array}$ & $\begin{array}{l}\text { Tensile Strength } f_{\mathrm{ctm}} \\
{[\mathrm{MPa}]}\end{array}$ & $\begin{array}{l}\text { Modulus of Elasticity } E_{\mathrm{cm}} \\
{[\mathrm{GPa}]}\end{array}$ \\
\hline $\mathrm{BZ} / \mathrm{P}+\mathrm{S}$ & & & 35.00 \\
\hline Bottom & 47.01 & 3.57 & 34.40 \\
\hline Top & 44.37 & 3.36 & 35.41 \\
\hline $\mathrm{BZ} / \mathrm{P}$ & & & 33.73 \\
\hline Bottom & 48.87 & 3.43 & \\
\hline Top & 41.54 & 3.18 & 34.67 \\
\hline BZ/S1 & & 34.02 \\
\hline Bottom & 45.55 & 3.04 & 37.13 \\
\hline Top & 42.76 & 3.06 & 36.63 \\
\hline BZ/S2/A and BZ/S2/B & & 340 \\
\hline Bottom & 57.25 & 3.56 & 545 \\
\hline Top & 54.72 & 3.49 & 200 \\
\hline $\begin{array}{l}\text { Stirrups yield } \\
\text { stress } f_{\text {ywm }}[\mathrm{MPa}]\end{array}$ & & \\
\hline $\begin{array}{l}\text { Longitudinal reinforcement } \\
\text { yield stress } f_{\text {ym }}[\mathrm{MPa}]\end{array}$ & & \\
\hline $\begin{array}{l}\text { Modulus of elasticity } \\
\text { of reinforcement } E_{\mathrm{s}}[\mathrm{GPa}]\end{array}$ & & & \\
\hline
\end{tabular}




\section{Test results}

\subsection{Crack pattern and failure mechanism}

The cracks morphology was investigated by documenting the cracks appearance on two beams of each series. Each of them was described and measured by the Brinell microscope. Measurements were made at each load step. Characteristic crack patterns for representative beams from various series after failure were shown in Fig. 3 and 4.

The cracking process, in all beams, began from vertical cracks, which appeared in the web. The first ones were located under the applied load, the next ones appeared in the zone of a constant moment. As the load increased, the diagonal cracks appeared, and they began to dominate the cracking process.

The largest widths were reached by the first diagonal cracks. Until the diagonal crack reached the interface (the load was about $70 \mathrm{kN}$ ) the crack pattern in all series looked similar.

Later, in the $\mathrm{BZ} / \mathrm{P}+\mathrm{S}$ series a local crack in the interface was observed, which propagated into the flange towards the support next. Beams of BZ/P series (without reinforcement) were characterized by violent delamination along the whole interface, after a diagonal crack reached it. At the point of load application in the flange, a vertical crack was formed which increased with the diagonal crack, despite the force drop below the value causing the interface crack.

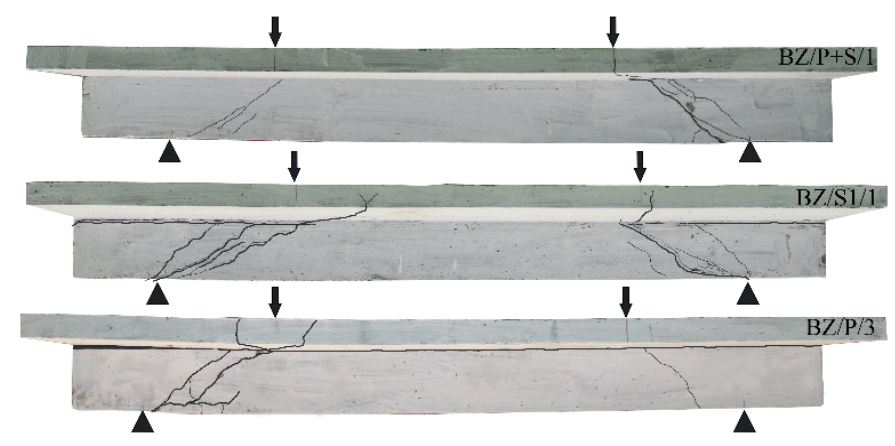

Fig. 3. Crack pattern of representative beams of the $\mathrm{BZ} / \mathrm{P}+\mathrm{S}, \mathrm{BZ} / \mathrm{S} 1$, and $\mathrm{BZ} / \mathrm{P}$ series after failure. Source: own study

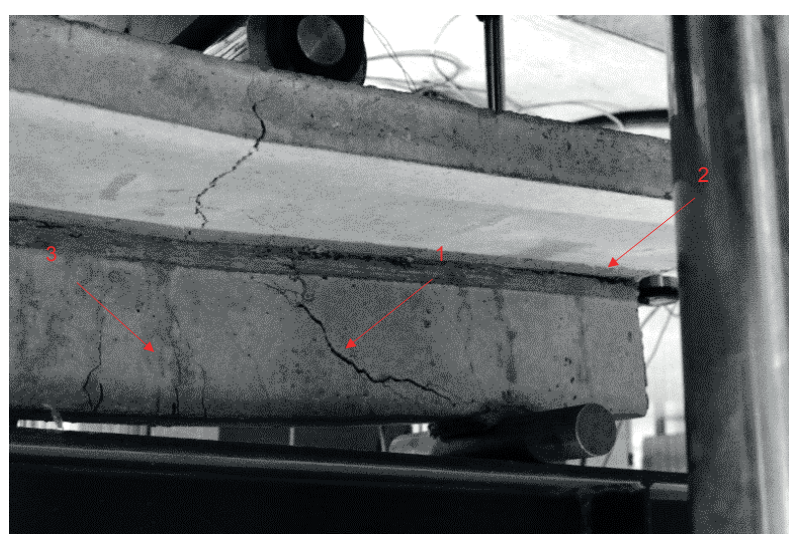

Fig. 4. Crack pattern of BZ/S2/B series with $\rho_{\mathrm{i}}=0.42 \%$ : 1 - diagonal crack, 2 - interface crack at the end of the beam, 3 - perpendicular cracks at the place of load application. Source: own study 
In the BZ/S1, BZ/S2/A, and BZ/S2/B series, where adhesion was limited or broken, the interface crack occurred just in the beginning of loading process and developed from the ends of the beams to the supports, joining the diagonal cracks upon reaching the interface. The static performance of the S1 and S2 series was very similar, however, due to the mechanical adhesion, the S1 series was characterized by higher values of the failure loads. In beams with broken adhesion, and with a higher joining reinforcement ratio (BZ/S2/B series), there were significantly more vertical cracks under the load locations and in the constant moment zone. These cracks as well as the diagonal cracks propagated and increased their width throughout the test to create a mixed failure mode - bending with shearing (Fig. 4).

In BZ/P, BZ/S1 and BZ/S2series of beams displacement of the flange and the web in relation to each other took place. It was measured using manual gauges with accuracy up to $0.01 \mathrm{~mm}$ located at the ends of the beam. Fig. 5 shows the relationship between the displacement and the applied load. Beams with adhesion and without joining reinforcement (BZ/P series) were characterized by a rapid increase of displacement at the moment of the interface crack and its intense growth with a slight increase of load. In series with joining reinforcement, but without adhesion (BZ/S1 and BZ/S2 series), the displacement of the components occurred, practically from the beginning of the loading process until the beam failure has been observed. Larger displacements usually occurred on the failure side of the beam. In the BZ/ $\mathrm{S} 1$ series (with limited adhesion) at the load of approximately $80 \mathrm{kN}$, and in the BZ/S2 series (with broken adhesion) at the load of $40 \mathrm{kN}$ (displacement was greater than the sensor range) was observed. The maximum displacement in beams with limited and broken adhesion was practically the same, observed at the load about $120-130 \mathrm{kN}$, but higher joining reinforcement ratio of the B-series caused that this displacement was growing up gently while on the curve corresponding to the A-series the rapid increase in displacement are visible.

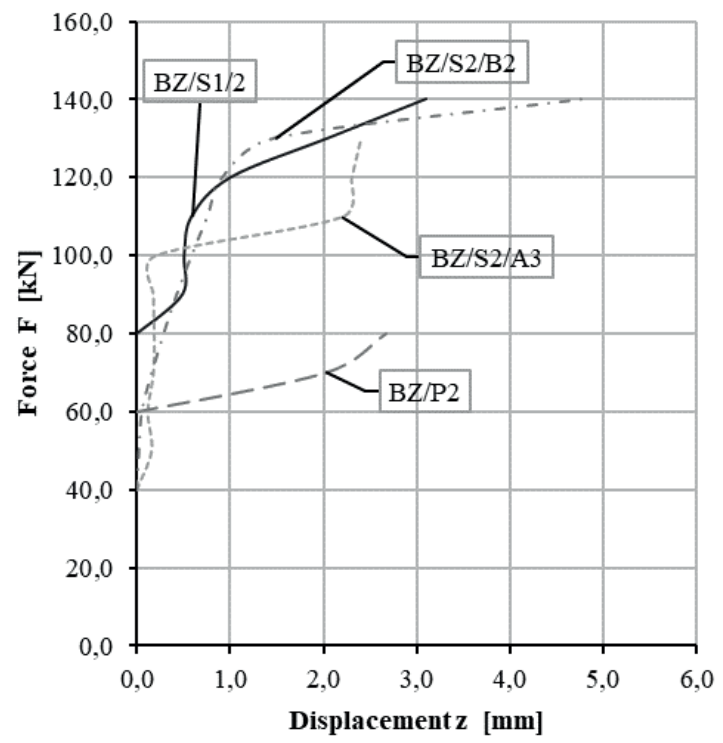

Fig. 5. Transverse displacement of the flange and the web in relation to each other on the beam end (a larger one from left and right side of the beam). Source: own study 
The main reinforcement strain chart (Fig. 6) shows that only bars of the BZ/S2/B series (broken adhesion, greater joining reinforcement ratio) have reached the yield point, which has a direct effect on the mixed mode of failure (failure due to shear with bending). Under the same adhesion conditions the beams BZ/S2/A series (lower joining reinforcement ratio) the yield strength was not reached, the beam was failed by a shear. In the BZ/P+S series (adhesion with joining reinforcement) the main reinforcement strain increased linearly and reached the highest load value. Also, in the BZ/P series of beams without joining reinforcement, a linear increase in strain was observed. It took place until the interface failed and was manifested by a rapid load decrease without strain increase. Next, the temporary relaxation of steel and resumption of the main reinforcement work in a separated part of the beam were observed.

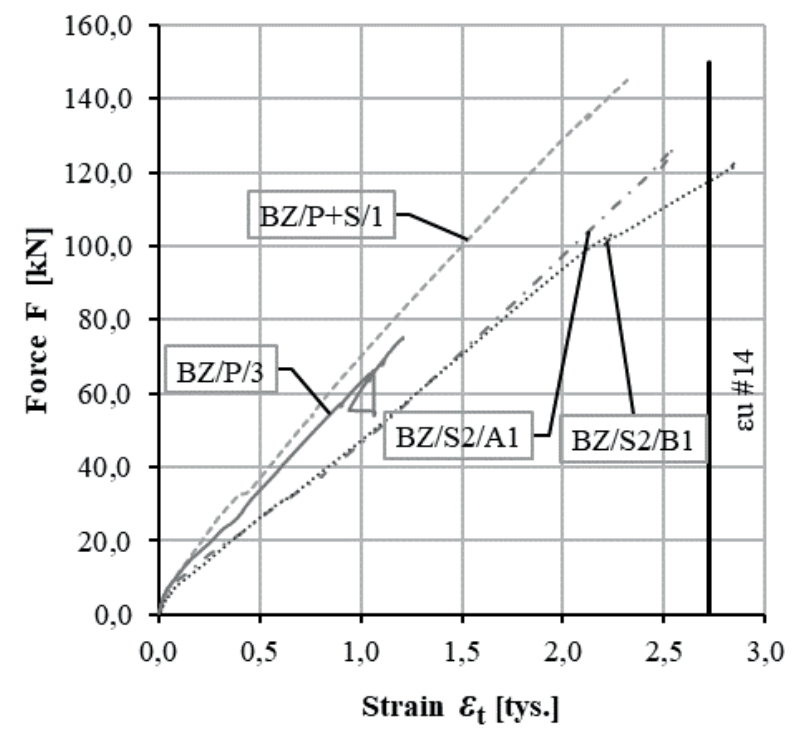

Fig. 6. Strain of the main reinforcement versus applied load, Ts3 strain gauge; $\varepsilon_{\mathrm{u}} \# 14$ - strain value corresponding to the yield strength of the main reinforcement. Source: own study

\subsection{Deflection}

Deflection was measured using linear variable differential transformer gauges (LVTD) located in the middle of the beam span and also at the ends for calibration purpose. Fig. 7 shows a summary of deflection versus applied load curves representative for the beams of each series. 


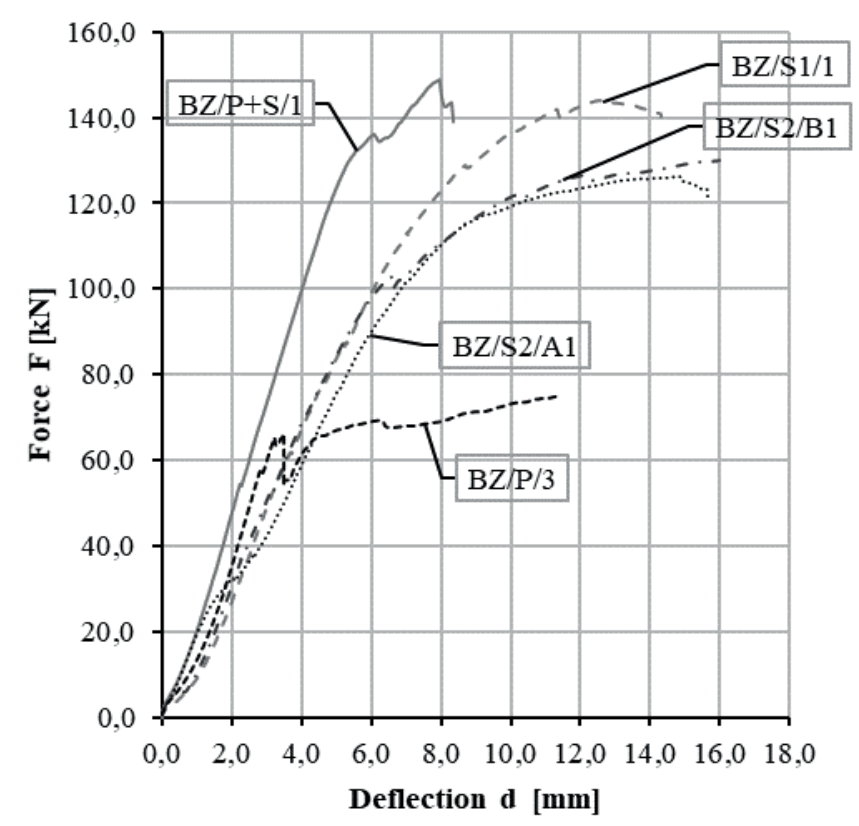

Fig. 7. Representative beams deflection from each series tested. Source: own study

The curve clearly shows the moment of the interface delamination of BZ/P series, manifested by a sharp drop in the load with a large increase in deflection.

In the $\mathrm{BZ} / \mathrm{P}+\mathrm{S}$ series there was also a drop of the curve but under higher load and deflection. This indicates the role of the stirrups. The "drop" was followed by enhancement - the successive activation of stirrups took place.

$\mathrm{BZ} / \mathrm{S} 1$ and BZ/S2 beams reached the highest deflection. In BZ/S1 series adhesion was limited by the use of anti-adhesive agents, which did not completely remove the adhesion (this is confirmed by the analysis of deflection). On the other hand, in the BZ/S2 series, in which adhesion was broken by PVC membrane, the deflections are higher with simultaneous reduction in the failure force.

\subsection{Strain of the stirrups}

The stirrups strain gauges were located in the interface level on the outside of the perimeter as shown in Fig. 1.

Comparing the stirrups strains and deflections of the beams in each series (Fig. 8), it can be observed that the characteristic points on the deflection diagrams at the moment of strain increase in the stirrups correspond to each other. It is shown with arrows in Fig.8.

In the beams of BZ/P+S series, the strain increases in the stirrups (Ts2, Ts5) begins at a force of about $55 \mathrm{kN}$, at which we can also observe the drop of the deflection curve. This can be identified with local interface crack. In further stages of loading, the stirrups strain in the support zone of BZ/P+S beams increase until the yield strength is reached. It is observed that the subsequent stirrups covered by a diagonal crack are engaged and the strain increases 
until the beam fails by shear. Value of the ultimate load of the beam is equal to the value of the load causing the yield of all last stirrup in the constant.

Attention should be paid to the performance of the transverse reinforcement in the support zone in the BZ/S2 series (broken adhesion), in which from the beginning of loading process there is an increase in strain noticeable. From subsequent charts it follows that as the load increases, further stirrups are activated. There is no uniform distribution of forces in the interface, so the stirrups reach the yield strength in sequence. In the BZ/S2/A and BZ/S2/B series, the first stirrup reaches the yield strength at the same load $(\sim 90 \mathrm{kN})$, then the next second one is activated, etc. Because there are more stirrups on the interface length in the $\mathrm{BZ} / \mathrm{S} 2 / \mathrm{B}$ series (higher reinforcement ratio) it allows beam performance at higher loads, until the yield strength of the main reinforcement is fully exploited. Characteristic for the BZ/S1 and $\mathrm{BZ} / \mathrm{S} 2$ series is also activation of the stirrups (Ts4) in the constant moment zone. Stirrups in the other beams achieved low levels of strain values in this zone. 
Influence of the interface reinforcement on static performance of concrete composite...
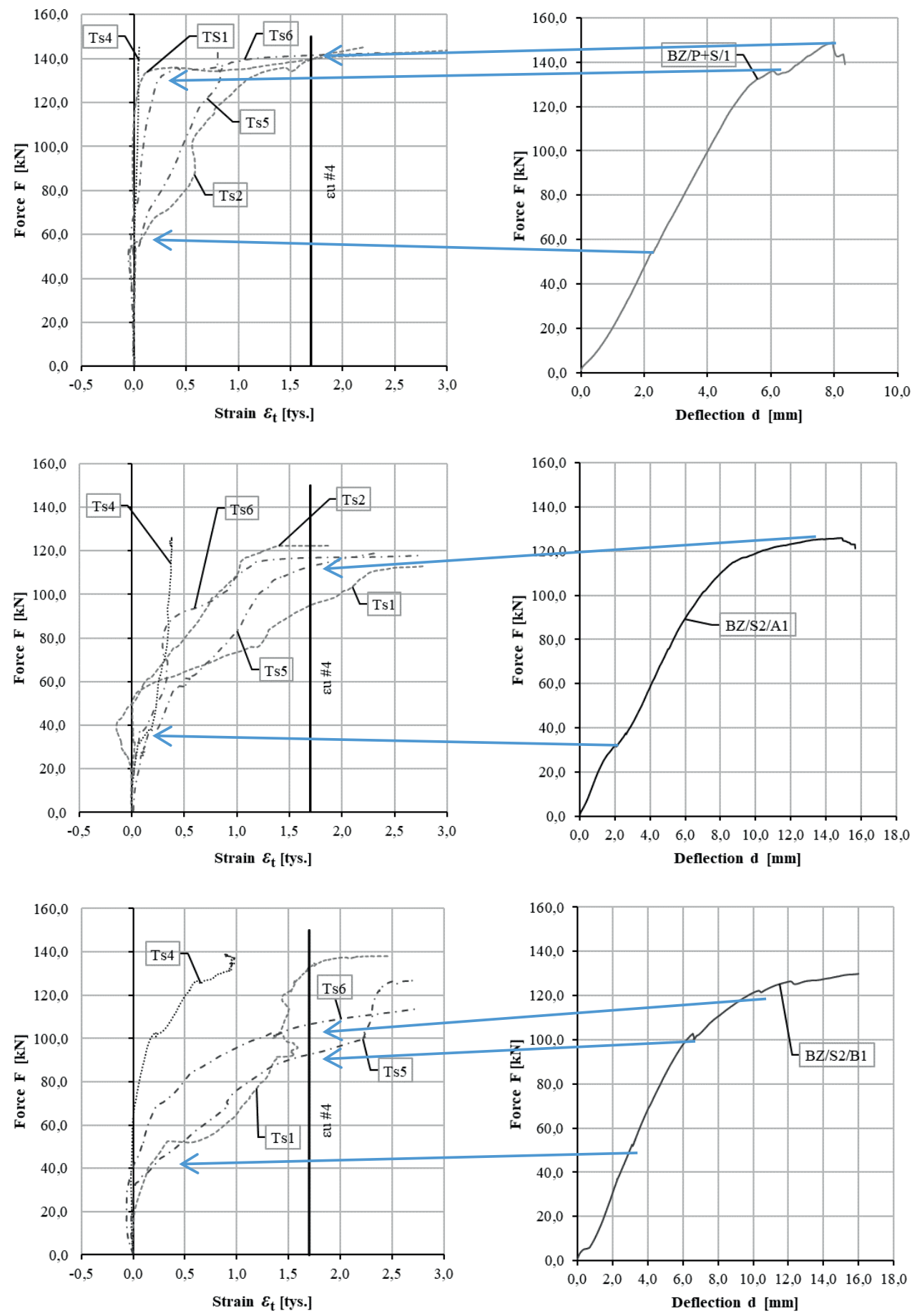

Fig. 8. Comparison of the reinforcement strain and deflection from each series tested; Ts1, Ts2 - stirrups on the left side, Ts 4 - stirrup in the constant momentum zone, Ts5, Ts6 - stirrups on the right side, $\varepsilon_{\mathrm{u}} \# 4$ - strain corresponding to the yield strength of stirrups. Source: own study 


\section{Analysis of the results}

\subsection{Dependence between interface crack pattern and failure mechanism of beam}

The crack pattern of the beams indicates that interface cracks arise at its various places and depend on the distribution of internal forces in the interface (values of normal and tangential stresses) and on the way the interface was arranged.

In the beams of the $\mathrm{BZ} / \mathrm{P}+\mathrm{S}$ series (with guaranteed adhesion and joining reinforcement), the crack in the interface appeared on a short length, at a load value of $47-51 \%$ of the ultimate load. It was a part of the diagonal crack. Then it passed into the flange and the beam was failed by shear in the support zone.

In the BZ/S1 and BZ/S2 series (reinforced interface with limited or without adhesion), the interface cracking process was characterized by delamination at the beam ends in the initial loading stage. The observed phenomenon was caused by tensile stress, normal to the contact surface, arising at the ends of simply supported beams in the four-point bending test. By using PVE membrane, the chemical adhesion of the concrete was broken and the tensile normal stress prevented the activation of mechanical adhesion. Joining reinforcement remained the main factor resulting in the interface ultimate load. In the support zone, the distribution of interface forces (shear and compression) and the existence of the transverse reinforcement allowed the transfer of loads as a result of mechanical adhesion and the phenomena of shear friction and dowel action. Despite the delamination of the ends and cracking of the interface over a considerable length, the beams still carried loads but underwent various forms of failure. Depending on the reinforcement ratio in the support zone, in BZ/S2/A series $\left(\rho_{\mathrm{i}}=0.21 \%\right.$ ), shear failure occurred and in $\mathrm{BZ} / \mathrm{S} 2 / \mathrm{B}$ series $\left(\rho_{\mathrm{i}}=0.42 \%\right)$, beams were failed in a mixed way by bending combined with shear.

The BZ/P series (guaranteed adhesion, no joining reinforcement) beams behaved differently. After the cracking stress was reached, the load bearing capacity of the interface was lost on the entire length. The beams were destroyed violently by the interface delamination.

Thus, depending on how the interface was formed, the crack pattern and the static performance of the composite depends.

\subsection{Ultimate load service of the interface according to fib Model- Code2010}

Using the classical equations of the layered structure theory, in order to comparison with the data obtained from the tests, the transverse force corresponding to the interface crack and its bearing capacity was calculated according to formula (1):

$$
\begin{aligned}
& V_{R d i}=\tau_{R d i} \cdot b_{j} \cdot \frac{\Delta_{11} \cdot\left(E_{p} J_{p}+E_{n} J_{n}\right)}{w_{0}} \\
& \Delta_{11}=\frac{1}{E_{p} A_{p}}+\frac{1}{E_{n} A_{n}}+\frac{w_{0}{ }^{2}}{E_{p} J_{p}+E_{n} J_{n}}
\end{aligned}
$$

where: $w_{0}-$ is the distance between the centroids of connected layers, $E_{\mathrm{cp}}, A_{\mathrm{p}}, J_{\mathrm{p}}$ and $E_{\mathrm{cn}}, A_{\mathrm{n}}$, $J_{\mathrm{n}}$ - the modulus of elasticity, the cross-sectional area and moment of inertia of "new" and "old" concrete, respectively. 
Using the methodology of the pre-standard fib Model Code 2010, based on the lesser of the compressive strength of the components $f_{\text {ck,min }}$ and the joining reinforcement ratio, the interface ultimate load was calculated. The interface in this standard is treated as non-rigid when the reinforcement degree $\rho_{i} \geq 0.05 \%$. Such conditions correspond to the interface of the $\mathrm{BZ} / \mathrm{P}+\mathrm{S}, \mathrm{BZ} / \mathrm{S} 1$ and $\mathrm{BZ} / \mathrm{S} 2$ series. Then the ultimate shear stress $\tau_{\mathrm{Rdi}}$ is calculated according to the formula:

$$
\tau_{R d i}=c_{r} f_{c k}^{1 / 3}+\mu \sigma_{N}+\rho \kappa_{1} f_{y d}(\mu \sin \alpha+\cos \alpha)+\kappa_{2} \cdot \rho \sqrt{f_{y d} \cdot f_{c d}}
$$

where $\mu$ - friction coefficient in the interface, $\zeta$ - the angle of the joining reinforcement to the surface of the interface, $\rho$ - the joining reinforcement ratio, $f_{y d}-$ yield strength of the joining reinforcement, $\mathrm{f}_{\mathrm{cd}}-$ compressive strength of concrete under triaxial loading conditions, $\kappa_{1}$ and $\kappa_{2}$ - coefficients, which take into account the fact that the joining reinforcement is subjected to the shear and bending simultaneously, and the relation of these stresses depends on the displacement (slip) in the interface.

In the case of the rigid interface (non-reinforced or if $\rho_{\mathrm{i}} \leq 0.05 \%$ ), which corresponds to the $\mathrm{BZ} / \mathrm{P}$ series, the limit shear stress $\tau_{\mathrm{Rdi}}$ is described by the equation:

$$
\tau_{R d i}=c_{a} f_{c t d}+\mu \sigma_{n}
$$

where $c_{a}-$ coefficient dependent on the roughness of the surface, $\mu$ and $\sigma_{n}-$ as in the formula (3).

The transverse forces corresponding to the interface ultimate load are summarized in Table 2. In order to allow the comparison of calculated and tested loads, the characteristic values of concrete compressive $f_{\text {ck }}$ and tensile $f_{\text {ctk } 0,05}$ strength as well as steel yield $f_{\text {yk }}$ stress, assessed on the basis of Table 1, are applied in equations (3) and (4). The characteristic value of the adhesion component $\mathrm{c}_{\mathrm{r}} \mathrm{f}_{\mathrm{ck}}{ }^{1 / 3}$ was calculated regarding safety coefficient $\gamma_{\mathrm{coh}}=2,0$ according to [14].

The most reliable series in the context of interface ultimate load is BZ/P, because its ultimate load depends only on adhesion, without additional effects resulting from the use of joining reinforcement. Achievement of the interface ultimate load (interpreted as contact delamination over the entire length) is equal to the ultimate load of the entire beam.

In the other examined beams, the point of the yielding stress in stirrup as the achievement of the interface ultimate load was set.

The above observations show that the standard calculation models for the interface ultimate load are applicable to elements subjected to longitudinal shearing alone rather than beams working mainly under combination of shear and bending. The local interface ultimate load, understood as the achievement of the yielding stress in one stirrup, does not cause failure of the beam because the next stirrup (further from the support) is turned on; moreover, there is less transverse force, so it can be loading again until the yielding stress in the second stirrup will be reached.

In addition, significant discrepancies in the tested and theoretical values may result from the fact that the interface ultimate load was calculated under the standard assumptions of the values of the factors $c_{a}$ and $c_{r}$, moreover, without taking into account the friction from normal stresses $\sigma_{\mathrm{n}}$. This indicates the main problem in the description of the behavior of reinforced concrete composite beams and, consequently, in the design of such beams. This problem is the lack of a precise description of the stress state prevailing in the interface of elements working in different schemes and imprecise values of the coefficients. To describe the actual behavior 
of the beam, it is therefore necessary to determine the appropriate values of coefficients and to know the complex stress state prevailing in the interface.

Table 2. Comparison of the forces causing failure and the standard values calculated according to $f i b$ Model Code 2010. Source: own study

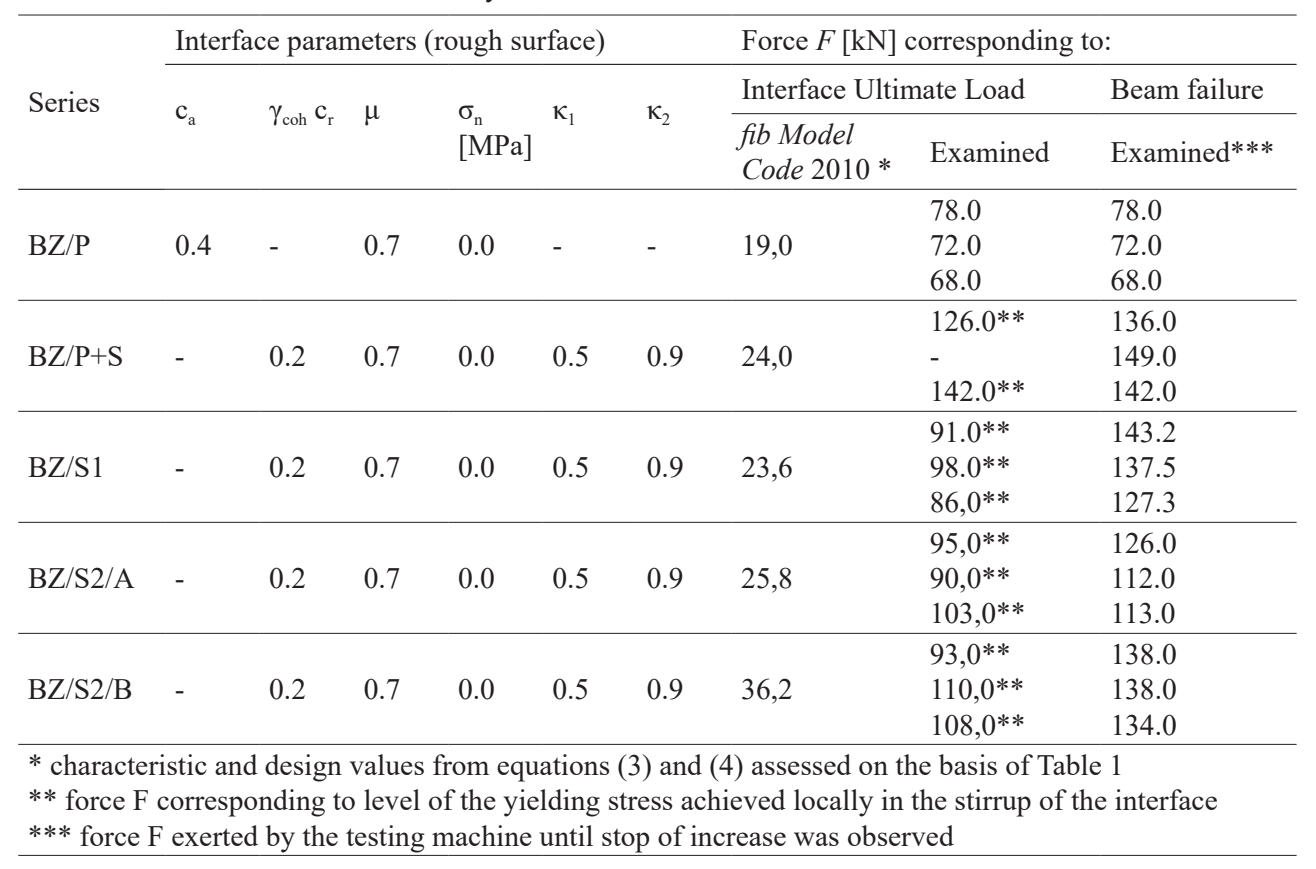

\section{Conclusions}

Based on the studies and analyses carried out, it can be stated that:

1. Achieving the yield strength of successive stirrups in the joint may indicate that the local interface ultimate load has been reached, however, it does not determine the beam ultimate load.

2. The standard models for the interface ultimate load calculation are applicable to elements subjected to longitudinal shearing alone rather than beams working mainly under combination of shear and bending. The achievement of the yielding stress in stirrup assumed in this model as the reason of joint failure means the local failure only. Then the next stirrup is turned on and the increase of load is possible.

3. The examination of beams with limited or broken adhesion in the interface allowed to conclude that:

a. Joining reinforcement remained an important factor resulting in the interface ultimate load in non-rigid connection. This reinforcement allows the transfer of loads between connected parts due to the phenomena of shear friction and dowel action. Despite the delamination in the interface the beams still carried loads but underwent various forms of failure.

b. In beams with a higher joining reinforcement ratio (BZ/S2/B series), there were significantly more vertical cracks under the load locations and in the constant moment zone than in the BZ/S2/A beams with lower reinforcement 
ratio. Increasing the joining reinforcement ratio may change the failure mode. The BZ/S2/A series beams (lower joining reinforcement ratio) failed by shear, whereas in the BZ/S2/B series the mixed mode of failure (failure due to shear with bending) was observed.

c. Higher joining reinforcement ratio of the B-series caused that displacement of connected parts in relation to each other was growing up gently while on the curve corresponding to the A-series the rapid increase in displacement was observed.

d. In spite of the eliminated adhesion in the interface of the BZ/S2/B series (with higher degree of the stirrups) the ultimate load was achieved similar to the level obtained by the beam with adhesion in the interface.

\section{References}

[1] Halicka A., Studium stanu naprężeń i odkształceń w płaszczyźnie styku i strefie przypodporowej elementów zespolonych z udziałem betonów skurczowych i ekspansywnych. Wydawnictwo Politechniki Lubelskiej, Lublin, 2007.

[2] Gromysz K., "Distribution of forces in composite concrete slab between the joint and the reinforcement anchored on the support", in Concrete and Concrete Structures 2013 Conference Procedia Engineering, 65, 2013, pp. 206-211.

[3] Kmiecik P., Kamiński M., "Modelling of reinforced concrete structures and composite structures with concrete strength degradation taken into consideration", Archives of Civil and Mechanical Engineering, vol. 11, no. 3, 2011, pp. 623-636.

[4] Sadowski G., Wiliński P., "Badanie wpływu ukształtowania styku na ugięcie żelbetowych belek zespolonych”, Inżynieria i Budownictwo, vol. 4, 2017, pp. 206-210.

[5] Tan K.H. et al., "Horizontal Shear Strength of Indirectly Loaded Composite Concrete Beams", ACI Structural Journal, 1999, pp. 533-538.

[6] Mahmoud M.A., Elafandy T.H., Okail H.O., Abdelrahman A.A., "Interfacial shear behavior of composite flanged concrete beams", HBRC Journal, vol. 10, 2014, pp. 206-214. https://doi. org/10.1016/j.hbrcj.2013.11.001

[7] Cavaco E., Pacheco I., Camara J. "Detailing of concrete-to-concrete interfaces for improved ductility”, Engineering Structures, vol. 156, 2018, pp. 210-223. https://doi.org/10.1016/j. engstruct.2017.10.058

[8] Jabłoński Ł., "Wpływ położenia styku na wysokości żelbetowych elementów zespolonych o przekroju teowym na stan graniczny zarysowania styku", Budownictwo i Architektura, vol. 13, no. 3, 2014, pp. 95-102. https://doi.org/10.35784/bud-arch.1770

[9] Halicka A., Jabłoński Ł., "Shear failure mechanism of composite concrete T-shaped beams", in Proceedings of the Institution of Civil Engineers - Structures and Buildings, vol. 169, no. 1, 2016, pp. 67-75. https://doi.org/10.1680/stbu.14.00127

[10] Halicka A., Jabłoński Ł., "Styk między betonami układanymi w różnym czasie - parametry i nośność według fib Model Code 2010”, Inżynieria i Budownictwo, vol. 7, 2015, pp. 346-350.

[11] Jabłoński Ł., "Numerical analyses and laboratory testing of concrete composite T-shaped beams without interface adhesion", in AIP Conference Proceedings, 1922(1), 2018. https://doi. org/10.1063/1.5019139

[12] Jabłoński Ł., "Numerical analyses of concrete composite T-shaped beams with variously arranged interface", in Proceedings of the $12^{\text {th }}$ International PhD Symposium in Civil Engineering. Prague, Czech Republic, 2018, pp. 441-448. 
[13] Jabłoński Ł., Halicka A., "Influence of surface based cohesive parameters on static performance of concrete composite T-shaped beams", MATEC Web of Conferences, vol. 262, 2019, pp. 1-7. https://doi.org/10.1051/matecconf/201926208003

[14] Randl N., Wicke M., "Schubübertragung zwischen Alt- und Neubeton”, Beton und Stahlbetonbau, vol. 95 , no. 8,2000 . 